\title{
EKOLEKSIKON MAULID ADAT BAYAN LOMBOK UTARA SEBAGAI SUPLEMEN BAHAN PEMBELAJARAN BAHASA INDONESIA BERBASIS LINGKUNGAN DI SMA
}

\author{
Deny Prasetiawan \\ Universitas Mataram \\ Awandeny8@gmail.com
}

\begin{abstract}
Abstrak
Bahasa dan budaya mendeskripsikan sebuah bangsa. Harusnya pepatah ini masih terpatri dalam setiap sanubari rakyat Indonesa. Penelitian ini bertujuan; 1) untuk mendeskripsikan bentuk dan kategori leksikon di dalam tradisi MAB; 2) untuk menemukan makna dan keterkaitan leksikon MAB; 3) untuk merevitalisasi bahasa yang menandai tradisi MAB sebagai suplemen bahan pembelajaran bahasa Indonesia berbasis lingkungan di SMA. Teori yang digunakan untuk membedah masalah tersebut adalah ekolinguistik, morfologi, semantik dan kebudayaan. Penelitian ini bersifat deskriptif kualitatif yaitu mengungkapkan fenomena kebahasaan yang terjadi dalam masyarakat setempat. Metode pengumpulan data dilakukan dengan metode observasi, dokumentasi dan wawancara. Bentuk leksikon yang ditemukan dalam prosesi MAB adalah bentuk dasar dan kompleks, sementara kategori yang ditemukan adalah kategori nomina biotik dan abiotik. Makna dan keterkaitan leksikon secara kultural yang tedapat dalam penelitian ini meliputi makna dan keterkaitan tehadap agama, alam, dan sosial. MAB berfungsi meningkatkan hubungan baik dengan sesama sehingga dapat dinyatakan bahwa proses MAB tersebut sebagai penuntun masyarakat dalam berperilaku di lingkungan masyarakat agar senantiasa berbuat baik. Hasil analisis menunjukkan bahwa penelitian ini akan dijadikan sebagai suplemen bahan pembelajaran bahasa Indonesia berbasis lingkungan di SMA yang diwujudkan dalam bentuk pembelajaran teks dengan tujuan agar dapat memberikan bekal pengetahuan, keterampilan dan prilaku kepada peserta didik.
\end{abstract}

Kata kunci: Ekolinguistik, Leksikon, dan Maulid Adat Bayan

\begin{abstract}
Language and cultur description the nation. Supposedly this aphorism still inherent in every heart of Indonesian people. Purpose of this study; 1) to description the form and category lexicon; 2) to found meaning and relation lexicon in MAB; 3) relevance in the MAB procession in revitalizing as a supplement Indonesian learning materials based on high school environment. The theory is used to dissect the problem is eco-linguistics, morphology, semantics and culture. This research is descriptive qualitative that express linguistic phenomena that occur in the local community. The data collection examineted by observation, documentation, and interview. Forms lexicon found in procession MAB was the basic form and shape of the complex, the category that found was the noun category biotic, abiotic. The meaning and relevance of cultural lexicon (culture) in this study included the meaning and relevance to God (religion), natural and human (social). The function of $M A B$ process was to improve relationships with others, it could be stated that the process of the $M A B$ as a guiding communities behave in society to always do something good. This study will be used as an Indonesian learning material supplement based on high school environment that realized in the form of text with the aim of learning in order to provide of knowledge, skills, and behaviors to students.
\end{abstract}

Keywords: Eco-linguistics, Lexicon, and Bayan Maulid Tradition

\section{PENDAHULUAN}

Bahasa selalu mengalami perubahan seiring dengan perubahan kebudayaan dan lingkungannya. Hal ini menjelaskan bahwa, budaya yang ada di sekeliling bahasa tersebut akan ikut menentukan bentuk bahasa tersebut. Bahasa dan budaya merupakan dua hal yang tidak dapat dipisahkan kerena saling memengaruhi dan saling mengisi (bandingkan Sibarani, 2004: 4). Oleh karena itu bahasa juga merupakan karakter yang 
mendefinisikan manusia, maka jelaslah bahwa bahasa dan manusia adalah dua unsur yang tak dapat dipisahkan.

Manusia hidup berinteraksi, bergantung pada lingkungan dengan segala isinya karena ada bahasa. Isi lingkungan adalah tumbuh-tumbuhan dan hewan serta lingkungan yang memengaruhi perkembangan manusia, membentuk karakter dan kepribadian manusia dan bisa juga disebut sebagai kebudayaan atau adat istiadat. Dengan kata lain manusia, bahasa, lingkungan (alam sekitarnya), dan budaya adalah satu mata rantai yang tak dapat dipisahkan. Hubungan yang bergantung atau keterkaitan tersebut sudah kodratnya atau dapat dikatakan sudah alamiah seperti itu. Bahasa, lingkungan alam, dan budaya berbagai etnik itu terekam dan terwarisi secara verbal dan nonverbal dalam bahasabahasa lokal termasuk dalam bahasa dan budaya Sasak di Lombok. Bahasa dan budaya merupakan warisan leluhur yang masih ada di tengah-tengah masyarakat, karena budaya merupakan tatanan yang mengatur kehidupan masyarakat secara turun temurun. Masyarakat yang berbudaya lebih tertib dalam menjalankan berbagai persoalan kehidupan bermasyarakat. Begitu pula budaya yang masih dipakai masyarakat diberbagai daerah di Indonesia, khususnya Sasak di Lombok. Untuk mengkaji hal itu, diperlukan sebuah teori, yakni ekolinguistik kerena ekolinguistik merupakan disiplin ilmu untuk mengkaji hubungan timbal-balik antara bahasa dengan lingkungan manusia/ sosial dan lingkungan alamiah. Dengan menggunakan teori ekolinguistik ini diharapkan dapat menguak kembali makna dan keterkaitan yang tekandung dalam bahasa atau leksikon yang digunakan pada tradisi ataupun budaya yang ada di Lombok.

Bayan adalah sebuah desa di sekitar hutan yang terletak di sisi barat daya Pulau Lombok, berada di kaki Gunung Rinjani, yang dikenal dengan penduduk asli Suku Sasak dan kini telah menjadi Subetnik Bayan ini memiliki loyalitas terhadap adat istiadat dalam banyak hal, pola dan tata cara berbudaya. Orang Sasak, leluhur asli orang Bayan sekarang, merupakan pemilik kebudayaan yang unik dan sakral. Mayoritas penduduknya memeluk agama Islam, dikenal dengan sebutan Islam wetu telu. Hal tersebut bisa dilihat dari bangunan-bangunan peninggalan bersejarah Islam, seperti Masjid Kuno dan upacaraupacara adat keagamaan wetu telu di Bayan yang ada sejak abad ke-16.

Seperti pada masyarakat lainnya, kehidupan subetnik Bayan dilandasi oleh kebudayaan asli yang mereka miliki sejak beratus-ratus tahun yang lalu. Hal ini terlihat dalam upacara-upacara adat, seperti upacara adat perkawinan, seni musik, seni tari, pakaian tradisional, permainan rakyat, makanan dan sebagainya yang terekam dan terepsentasikan dalam bahasa Sasak. Upacara adat yang terdapat dalam masyarakat Bayan merupakan ungkapan dari perilaku, cita-cita, kepribadian, dan 
pegangan hidup masyarakatnya dan hal ini dimaknai dan dijembatani melalui leksikon, perlengkapan dan tata cara pelaksanaannya. Bahasa yang digunakan oleh masyarakat Bayan juga termasuk bahasa yang arkais kerena bahasa yang digunakan di Bayan sangat jauh berbeda dengan bahasa Sasak pada umumnya sebagai variasi sosial ragam bahasa yang digunakan di Bayan, tergolong "ragam beku" (frozen style). Hal inilah yang melandasi dipilihnya Bayan sebagai lokasi penelitian.

Dalam pelaksanaan upacara-upacara adat, masyarakat Bayan menggunakan leksikon-leksikon sebagai kode lingual dan alat pengungkap yang merepresentasikan pikiran dan perasaan mereka. Salah satu contoh adalah pada tradisi Maulid Adat Bayan yang dilakukan oleh masyarakat di Bayan yang selanjutya disingkat MAB. Pelaksanaan tradisi MAB ini berjalan selama dua hari. Hari pertama adalah persiapan bahan makanan dan piranti upacara lainnya yang disebut "kayu aiq", sementara hari kedua adalah do'a dan makan bersama yang dipusatkan di Masjid Kuno Bayan yang disebut "gawe". Perhitungan pelaksanaannya berdasarkan Sereat Adat Gama di Bayan. MAB dilaksanakan pada dua hari setelah ketetapan Kalender Islam Maulid Nabi tanggal 12 Rabi'ul Awal tepatnya dimulai pada tanggal 14-15 Rabi'ul Awal. Masyarakat Bayan setempat biasa menyebutnya dengan "Mulud Adat Bayan".

Tradisi MAB ini mempunyai berbagai bentuk leksikon yang merepresentasikan maksud dan tujuan serta makna tertentu yang berhubungan dengan agama, alam, sosial dan lingkungan. Misalnya pada hubungan sosial digunakan leksikon Inan Meniq (Inan asal kata Inaq berarti Ibu, Meniq berarti beras), yaitu seorang perempuan yang menerima hasil bumi dari para warga yang nantinya hasil bumi tersebut akan diolah menjadi hidangan (sajian) untuk dihaturkan kepada ulama dan tokoh adat Sasak Bayan keesokan hari. Akan tetapi seiring perkembangan zaman dan melihat kodisi terakhir saat peneliti melakukan obesrvasi awal, MAB ini sedikit mengalami pergeseran, mulai dari leksikon yang tidak digunakan, dan kelengkapankelengkapan saat prosesi berlangsung maupun dari tata cara pelaksanaannya. Selain itu, pemuda di Bayan banyak sekali yang lupa dan sedikit sekali yang mengetahui leksikon, kelengkapankelengkapan maupun prosesi lengkap pada tradisi MAB. Hal ini sungguh memprihatinkan. Di sisi lain pengetahuan masyarakat tentang tradisi MAB belum diajarkan secara menyeluruh, baik dalam keluarga, masyarakat dan jalur formal, sehingga terjadi kesenjangan pengetahuan antara yang tua dan yang muda. Padahal bila dikaji dan dianalisis, leksikon yang digunakan dalam tradisi tersebut mengandung makna dan nilai-nilai filosofis. Sinar (2010:70) menyatakan bahwa "banyak bahasa daerah di Indonesia berada di ambang kritis, semakin sulit untuk 
"hidup", bertahan, berfungsi, dan terwaris secara utuh, belum lagi dengan ancaman hegemoni dan dominasi beberapa bahasa nasional dan internasional yang semakin mendesak bahasa-bahasa minoritas".

Kondisi tersebut tentulah sangat memprihatinkan karena budaya yang hilang akan turut menghilangkan leksikon bahasa daerah. Jika kondisi tersebut terus dibiarkan tanpa adanya upaya untuk mempertahankan ataupun melestarikannya, MAB yang ada di Kecamatan Bayan Lombok Utara akan kehilangan sebuah warisan leluhur, jati diri dan identitas yang sangat berharga. Untuk itu, peneliti merasa penting dan tertarik untuk lakukan penelitian guna mengugkap kembali makna dan nilai filosofis dalam tradisi MAB yang terdapat di Kecamatan Bayan Lombok Utara. Hal ini menjadi penting untuk dikaji kerena bahasa dan budaya merupakan salah satu kekayaan Indonesia yang perlu untuk dipertahankan dan dilestarikan. Selain itu suatu budaya penting untuk dipertahankan karena sarat akan makna dan nilai. Dengan demikian budaya dan kekayaan leksikon akan terselamatkan dan terhindar dari kepunahan.

Bersinggungan dengan fenomena itu, upaya sederhana yang dapat dilakukan untuk mempertahankan tradisi MAB adalah dengan mengembangkan materi pembelajaran bahasa Indonesia berbasis lingkungan di sekolah, dalam hal ini merujuk dari Mbete, SNBI VII (2003: 17) yang mengatakan secara khusus parameter-parameter ekolin- guistik, konsep "ekologi bahasa dan bahasa ekologis" yang diusulkan untuk diterapkan dalam membangun model pembelajaran bahasa-bahasa. Dalam hal ini pembelajaran bahasa-bahasa berbasis lingkungan. Hal ini perlu karena di KLU masih belum diajarkan secara menyeluruh tentang pembelajaran bahasa Indonesia berbasis lingklungan, dengan dasar pemikiran jika kehidupan sosial-tradisional keetnikan tetap diberi ruang dan peluang untuk hidup dan berperan, niscaya bahasa-bahasa daerah tidak mesti terancam punah. Penerapan pembelajaran tersebut tentu saja harus sesuai dengan kurikulum pendidikan, yakni kurikulum yang berakar pada budaya lokal dan bangsa, yang memiliki arti bahwa kurikulum harus memberikan kesempatan kepada peserta didik untuk belajar dari budaya setempat dan nasional tentang berbagai nilai hidup yang penting.

Berdasarkan latar belakang yang telah dipaparkan di atas, maka rumusan masalah dalam penelitian ini secara rinci dapat diuraikan sebagai berikut. Bagaimanakah deskripsi bentuk-bentuk dan kategori leksikon yang digunakan pada tradisi MAB? Deskripsi bentuk-bentuk dan kategori leksikon leksikon yang dimaksud adalah pengelompokan leksikon-leksikon yang digunakan di MAB ke dalam kategori linguistik (morfologi yakni bentuk dasar dan kompeleks) dan kategori ekologi (biotik dan abiotik). Bagaimanakah makna dan keterkaitan leksikon prosesi kegiatan MAB terhadap lingkungan masyarakat Bayan? 
Makna dan keterkaitan leksikon prosesi kegiatan yang dimaksud di dalam rumusan masalah adalah makna dan keterkaitan fungsional leksikon prosesi kegiatan MAB yang merepresentasikan hubungan dengan agama, alam dan manusia (sosial). Bagaimanakah revitalisasi bahasa Sasak Bayan yang menandai tradisi MAB demi ketahanan dan keterlanjutan makna dan nilai dalam MAB sebagai suplemen bahan pembelajaran bahasa Indonesia berbasis lingkungan di SMA?. Penelitian ini bertujuan untuk mendeskripsikan bentukbentuk dan kategori leksikon MAB, menemukan makna dan keterkaitan leksikon-leksikon tersebut terhadap lingkungan masyarakat Bayan, dan yang terakhir untuk mengonsepkan revitalisasi bahasa yang menandai tradisi MAB demi ketahanan nilai-nilai kearifan lokal dalam MAB sebagai suplemen bahan pembelajaran bahasa Indonesia berbasis lingkungan di SMA.

\section{KONSEP DAN KERANGKA TEORI Konsep \\ Konsep Maulid Adat}

Bulan Rabi'ul Awal khususnya bagi umat Islam, diperingati sebagai bulan kelahiran Nabi Muhammad SAW, atau dikenal dengan Maulid Nabi. Berbagai kegiatanpun dilaksanakan. Ada sebagian masyarakat memamfaatkan untuk acara ngurisan (potong rambut) bagi bayinya yang baru lahir, ada juga yang melakukan khitanan anaknya untuk mengambil barokah dari datangnya bulan kelahiran
Baginda Nabi SAW. Suasana yang berbeda dalam peringatan ini adalah yang dilakukan oleh komunitas Adat Bayan Kabupaten Lombok Utara, dimana tradisi Maulid selama dua hari. Hari pertama adalah persiapan bahan makanan dan piranti upacara lainnya yang dikenal dengan istilah "kayu aiq". Sementara pada hari kedua mbisoq meniq, mengelaq, do'a dan makan bersama yang dipusatkan di Masjid Kuno Bayan. Prosesi pelaksanaan Mulud Adat Bayan Berdasarkan perhituangan Sareat (syari'at) Adat Gama Bayan.

\section{Teori}

Ekolinguitik sudah lama dipopulerkan oleh Haugen (1972) akan tetapi istilah ekolinguistik belum begitu memasyarakat, terutama pada sebagian linguis Indonesia. Istilah ini mulai menjadi paradigma baru sejak 1990 seiring dengan semakin kompleksnya permasalahan ekologi dunia sebagai dampak dari perubahan lingkungan. Ditinjau dari kata, ekolinguistik berasal dari dua kata yaitu ekologi dan linguistik. Ekologi adalah ilmu yang membahas tentang hubungan manusia dengan lingkungannya, sedangkan linguistik adalah ilmu yang mebahas tentang bahasa.

Ekolinguistik adalah suatu disiplin ilmu yang mengkaji lingkungan dan bahasa. Ekolinguistik merupakan ilmu bahasa interdisipliner, menyanding ekologi dan linguistik (Mbete, 2007:1). Disiplin ilmu ini mengkaji hubungan timbal-balik antara bahasa dengan lingkungan manusia/sosial 
dan lingkungan alamiah. Ekolinguistik merupakan suatu kajian yang membahas tentang bahasa yang dikaitkan dengan lingkungan di mana bahasa tersebut tumbuh, berkembang dan dipergunakan oleh masyarakat bahasa di daerah bahasa tersebut. Crystal 2008 (dalam Mbete 2013: 17) mengemukakan definisi ekolinguistik,

Ecolinguistics (n.) in linguistics, an emphasis- reflectiong the notion of ecology in biological studies- in which the interaction between language and cultural environment is seen as central; also called the ecology of language, ecological linguistics, and sometimes green linguistics, an ecolinguistic approach highlights the value of linguistics diversity in the world, the importance of individual and community linguistic rights, and the role of language attitudes, language awareness, language variety, and language change in fostering a culture of communicative peace.

Dalam pengertian tersebut, interaksi antara bahasa dan lingkungan budaya menjadi sangat penting di sisi nilai keberagaman bahasa, hak-hak kebahasaan perorangan dan kelompok, kesadaran, dan sikap tentang budaya komunikasi yang harmonis. Kajian ekolinguistik merupakan kajian kebahasaan, yaitu bahasa yang hidup karena digunakan, lisan ataupun tulisan sebagai fungsi sosial yang diemban oleh bahasa. Dimensi fungsi sosio-ekologis bahasa dalam perspektif ekolinguistik, bahasa tidak lagi diposisikan sebagai fakta dalam kajian linguistik formal, melainkan bahasa dalam kehidupan sehari-haripun dipandang sebagai fakta kebudayaan yang sarat makna. Di dalamnya termasuk kekayaan leksikon dengan kandungan makna-makna budaya para guyub tuturnya (speech community). Sapir (dalam Fill dan Muhlhausler, 2001:14) mengemukakan,

"it" is advantageous to comprise within the term environment both physical and social factors. Under physical environment are comprised geographical character such as the topography of the country (whether coast, valley, plain, plateau, or mauntain), climate, and amount of rainfall, and what may be called the economic basis of human life, under which term are comprised the fauna, flora, and mineralresaurce of the region. Under social environment are comprised the variousforces of society that mental the life and thought of each individual. Among the more important of the social forces are religion, ethical standart, form of political organization, and art.

Lingkungan bahasa dalam ekolinguistik meliputi lingkungan ragawi dan sosial Lingkungan ragawi menyangkut geografi yang terdiri atas fisik: topografi suatu negara (pesisir, lembah, daratan, dataran tinggi, gunung), iklim, dan intensitas curah hujan, dasar ekonomis kehidupan manusia yang terdiri atas fauna, flora, dan sumbersumber mineral; sedangkan lingkungan sosial terdiri atas berbagai kekuatan masyarakat yang membentuk pikiran dan kehidupan setiap individu di antaranya: agama, etika, bentuk organisasi politik, dan seni. Jadi dapat dibedakan bahwa ranah kajian ekolinguistik mencakup ketergantungan dalam suatu sistem. Teori tersebut didasari pada prinsip interaksi dan keberagaman (diversity). Bentuk interaksi antara lingkungan fisik dan lingkungan sosial atau bahasa dan kebudayaan dapat 
dilihat pada level interrelasi leksikon. Sedangkan bentuk keberagaman (diversity) dapat dilihat pada tatanan kebervariasian leksikon yang dihasilkan oleh suatu bahasa tersebut.

Morfologi merupakan cabang linguistik yang mengidentifikasikan satuan dasar dan turunan bahasa sebagai satuan gramatikal (Verhaar, 2010: 97). Sedangkan semantik adalah cabang linguistik mengkaji makna (Verhaar, 2010:385). Bidang semantik dibagi menjadi semantik leksikal dan semantik gramatikal. Dalam penelitian ini hanya digunakan teori semantik gramatikal. Semantik gramatikal menyangkut makna leksikon dalam bidang leksikon tertentu.

Bahasa dan budaya, Duranti (1997: 27) mengemukakan,

there is a linguistic homology at work here. To know a culture is like knowing a language. They are both mental realities. Furthermore, to describe a culture is like describing a language. Hence, the goal of ethnografhic descriptions is the writing of "cultural grammar"

Mencermati pendapat Duranti di atas, dapatlah dikemukakan di sini bahwa mengetahui budaya sama halnya mengetahui bahasa. Keduanya merupakan realitas mental. Selanjutnya, mendeskripsikan suatu budaya sama halnya dengan mendeskripsikan bahasa. Oleh karena itu tujuan etnografi adalah untuk menuliskan "grammar budaya". Mauss (1935, dalam Duranti, 1997: 26), mengatakan hubungan budaya dan bahasa dalam hal ini sangatlah erat bila ditinjau dari proses sosialisasinya yang terjadi dimana bahasa merupakan sesuatu yang membentuk pikiran dan tingkahlaku seseorang dalam berbicara, berfikir dan bertindak sehingga diterima oleh masyarakat luas, dimana hal ini merupakan budaya, yaitu dengan melihat tanda-tanda linguistik dapat menjelaskan adanya perbedaan status sosial yang dipergunakan oleh kelompok-kelompok tertentu. Bahasa dengan budaya mempunyai hubungan yang erat sekali. Mereka saling mempengaruhi, saling mengisi, dan berjalan berdampingan. Hubungan mendasar antara keduanya adalah bahasa harus dipelajari dalam konteks budaya dan budaya dapat dipelajari melalui bahasa (Sukri, 2008: 49). Jadi, melalui bahasa, manusia dapat menyesuaikan diri dengan adat istiadat, tingkah laku, tata karma masyarakat dan sekaligus membaurkan dirinya dalam masyarakat. Akan tetapi, bersandingnya bahasa dan budaya tidak serta merta menimbulkan keharmonisan. Jika salah satunya mendominasi maka itu juga merpakaan persoalan yang sangat perlu untuk diperhatikan.

\section{PEMBAHASAN}

Bulan Rabi'ul Awal khususnya bagi umat Islam, diperingati sebagai bulan kelahiran Nabi Muhammad SAW, atau dikenal dengan Maulid Nabi. Berbagai kegiatanpun dilaksanakan. Ada sebagian masyarakat memamfaatkan untuk acara ngurisan (potong rambut) bagi bayinya 
yang baru lahir, ada juga yang melakukan khitanan anaknya untuk mengambil barokah dari datangnya bulan kelahiran Baginda Nabi SAW. Suasana yang berbeda dalam peringatan ini adalah yang dilakukan oleh komunitas Adat Bayan Kabupaten Lombok Utara, dimana tradisi Maulid selama dua hari. Hari pertama adalah persiapan bahan makanan dan piranti upacara lainnya yang dikenal dengan istilah "kayu aiq". Sementara pada hari kedua mbisoq meniq, mengelaq, do'a dan makan bersama yang dipusatkan di masjid kuno Bayan. Prosesi pelaksanaan MAB dilaksanakan berdasarkan perhituangan Sareat (syari'at) Adat Gama Bayan, bahwa MAB dilaksanakan dua hari yaitu tanggal 14-15 Rabiul Awal dimana dalam penelitian ini MAB dilaksanakan pada 26-27 Desember 2015.

Hari pertama dikenal istilah Kayu Aiq. Pada hari Kayu Aiq ini, ada beberapa prosesi yang dilaksanakan yaitu;

1) Bebasan makanan

2) Nazar

3) Menyembeq
4) Ngalu Gerantung

5) Bisok Rantok

6) Menutu dan merantes

7) Buang unggun

8) Umbul-umbul

9) Ngengelat

\section{0)Temetian/Peresean}

Hari Kedua disebut dengan Gawe, Hari kedua ini bertepatan dengan tanggal 12 rabiul awal (Ton Jimawal), yakni tanggal 27 Desember 2015 adalah puncak acara. Pada acara gawe ini ada beberapa macam prosesi yang dilakukan yaitu;

1) Menampah hewan

2) Bisok meniq

3) Mengkelaq

4) Pengaluan Payung Agung

5) Ancak

6) Mengageq

7) Praja mulud

8) Khotbah

9) Memblonyo

10)Meriap

11)Melusut

Bentuk dan Kategori Leksikon MAB

\begin{tabular}{|l|l|l|l|l|l|l|}
\hline No & \multicolumn{2}{|c|}{ Bahasa } & \multicolumn{2}{c|}{ Bentuk Linguistik } & \multicolumn{2}{c|}{ Kategori Ekologi } \\
\hline & \multicolumn{1}{|c|}{ Sasak } & Indonesia & Bentuk & Leksikal & Biotik & Abiotik \\
\hline 1 & Ancak & $\begin{array}{l}\text { Tempat } \\
\text { menaruh } \\
\text { makanan } \\
\text { yang tebuat } \\
\text { dari bambu }\end{array}$ & Dasar & $\begin{array}{l}\text { Tidak } \\
\text { bernyawa }\end{array}$ & - & + \\
\hline 2 & Bebasan & Bahan & Dasar & $\begin{array}{l}\text { Tidak } \\
\text { bernyawa }\end{array}$ & + & - \\
\hline 3 & Bisok meniq & $\begin{array}{l}\text { Mencuci } \\
\text { beras }\end{array}$ & Majemuk & $\begin{array}{l}\text { Tidak } \\
\text { bernyawa }\end{array}$ & - & + \\
\hline 4 & Bisok Rantok & $\begin{array}{l}\text { Mencuci } \\
\text { tempat } \\
\text { menumbuk } \\
\text { padi }\end{array}$ & Majemuk & $\begin{array}{l}\text { Tidak } \\
\text { bernyawa }\end{array}$ & - & + \\
\hline 5 & Buang unggun & $\begin{array}{l}\text { Membuang } \\
\text { tempat } \\
\text { menaruh } \\
\text { sekam }\end{array}$ & Mejemuk & $\begin{array}{l}\text { Tidak } \\
\text { bernyawa }\end{array}$ & - & + \\
\hline
\end{tabular}


RETORIKA: Jurnal Ilmu Bahasa, Vol. 2, No.2 Oktober 2016, 241

\begin{tabular}{|c|c|c|c|c|c|c|}
\hline 6 & Khotbah & $\begin{array}{l}\text { Khotbah/ } \\
\text { ceramah }\end{array}$ & Dasar & $\begin{array}{l}\text { Tidak } \\
\text { bernyawa }\end{array}$ & - & + \\
\hline 7 & Melusut & $\begin{array}{l}\text { Membuka } \\
\text { kembali } \\
\text { kain } \\
\text { pajangan } \\
\end{array}$ & $\begin{array}{l}\text { Afiksasi, } \\
\text { preiks }\end{array}$ & $\begin{array}{l}\text { Tidak } \\
\text { bernyawa }\end{array}$ & - & + \\
\hline 8 & Memblonyo & $\begin{array}{l}\text { Memberika } \\
\mathrm{n} \text { minyak } \\
\text { blonyo }\end{array}$ & $\begin{array}{l}\text { Afiksasi, } \\
\text { preiks }\end{array}$ & $\begin{array}{l}\text { Tidak } \\
\text { bernyawa }\end{array}$ & - & + \\
\hline 9 & Menampah & $\begin{array}{l}\text { Menyembe } \\
\text { lih }\end{array}$ & $\begin{array}{l}\text { Afiksasi, } \\
\text { preiks }\end{array}$ & $\begin{array}{l}\text { Tidak } \\
\text { bernyawa }\end{array}$ & - & + \\
\hline 10 & Mengageq & $\begin{array}{l}\text { Menghidan } \\
\text { gkan }\end{array}$ & $\begin{array}{l}\text { Afiksasi, } \\
\text { preiks }\end{array}$ & $\begin{array}{l}\text { Tidak } \\
\text { bernyawa }\end{array}$ & - & + \\
\hline 11 & Mengkelaq & Memasak & $\begin{array}{l}\text { Afiksasi, } \\
\text { preiks }\end{array}$ & $\begin{array}{l}\text { Tidak } \\
\text { bernyawa }\end{array}$ & - & + \\
\hline 12 & $\begin{array}{l}\text { Menutu dan } \\
\text { merantes }\end{array}$ & Menumbuk & $\begin{array}{l}\text { Afiksasi, } \\
\text { preiks }\end{array}$ & $\begin{array}{l}\text { Tidak } \\
\text { bernyawa }\end{array}$ & - & + \\
\hline 13 & Menyembeq & $\begin{array}{l}\text { Menandai } \\
\text { dahi } \\
\text { dengan } \\
\text { sirih }\end{array}$ & $\begin{array}{l}\text { Afiksasi, } \\
\text { preiks }\end{array}$ & $\begin{array}{l}\text { Tidak } \\
\text { bernyawa }\end{array}$ & - & + \\
\hline 14 & Meriap & $\begin{array}{l}\text { Kegiatan } \\
\text { makan } \\
\text { bersama }\end{array}$ & $\begin{array}{l}\text { Afiksasi, } \\
\text { preiks }\end{array}$ & $\begin{array}{l}\text { Tidak } \\
\text { bernyawa }\end{array}$ & - & + \\
\hline 15 & Nazar & Nazar/niat & Dasar & $\begin{array}{l}\text { Tidak } \\
\text { bernyawa }\end{array}$ & - & + \\
\hline 16 & Ngalu Gerantung & $\begin{array}{l}\text { Menjemput } \\
\text { grantung } \\
\text { (alat } \\
\text { musik) }\end{array}$ & Majemuk & $\begin{array}{l}\text { Tidak } \\
\text { bernyawa }\end{array}$ & - & + \\
\hline 17 & Ngengelat & $\begin{array}{l}\text { Mendanda } \\
\text { ni Masjid } \\
\text { Kuno }\end{array}$ & $\begin{array}{l}\text { Afiksasi, } \\
\text { preiks }\end{array}$ & $\begin{array}{l}\text { Tidak } \\
\text { bernyawa }\end{array}$ & - & + \\
\hline 18 & $\begin{array}{l}\text { Pengaluan } \\
\text { Payung Agung }\end{array}$ & $\begin{array}{l}\text { Pemberian } \\
\text { payung } \\
\text { agung }\end{array}$ & Majemuk & $\begin{array}{l}\text { Tidak } \\
\text { bernyawa }\end{array}$ & - & + \\
\hline 19 & Praja mulud & $\begin{array}{l}\text { Muda mudi } \\
\text { yang dihias } \\
\text { menyerupa } \\
\text { i pengantin }\end{array}$ & Majemuk & Bernyawa & + & - \\
\hline 20 & $\begin{array}{l}\text { Temetian/ } \\
\text { Peresean }\end{array}$ & Prisian & Dasar & Bernyawa & + & - \\
\hline 21 & Umbul-umbul & $\begin{array}{l}\text { Umbul- } \\
\text { umbul }\end{array}$ & Ulang & $\begin{array}{l}\text { Tidak } \\
\text { bernyawa }\end{array}$ & - & + \\
\hline
\end{tabular}

\section{Makna dan Keterkaitan Leksikon Prosesi MAB di Lingkungan Masyarakat Bayan}

Berdasarkan sudut pandang dalam mengkaji obejek penelitian, maka makna leksikon yang dikemukakan dalam peneltian ini meliputi makna bahasa dan cultural (budaya). Makna bahasa dan cultural (budaya) yang ingin diungkapkan di dalam penelitian ini adalah makna yang tersurat maupun tersirat dari setiap leksikon yang digunakan di dalam MAB sebagai wujud tradisi yang diciptakan masyarakat Bayan. Rangkaian proses MAB mengandung berbagai makna yang mewakili cara masyarakat Bayan memandang lingkungan dan kehidupan di dalamnya. Berdasarkan data yang ditemukan, dapat dikatakan bahwa makna bahasa dan cultural (budaya) yang terdapat dalam MAB berhubungan dan berkaitan dengan nilai agama, alam, dan sosial. Secara umum kebudayaan di Bayan memiliki 7 unsur pokok. Unsur tersebut adalah; 1) sistem religi dan upacara keagamaan; 2) sistem kekerabatan; 3) sistem politik dan pemerintahan, 4) sistem tekhnologi dan peralatan hidup, 5) sistem 
Leksikon yang Berhubungan dan Berkaitan dengan Agama

\section{a. Mulud Adat Bayan}

Maulid berkaitan dengan perayaan hari kelahiran Nabi Muhammad SAW yang dilakukan oleh masyarakat Bayan yang beragama Islam. Kegiatan ini dilakukan setiap sekali dalam setahun oleh seluuh masyarakat beragama Islam, khususnya masyarakat Bayan. Kegiatan maulid ini dilaksanakan secara adat dan telah berlangsung secara turun temurun dari generasi ke generasi. Perayaan secara adat ini merupakan sesuatu hal yang sangat unik karena dalam ritual adat tersebut, kegiatan maulid adat ini tidak hanya diikuti oleh masyarakat yang beraga Islam saja, tetapi juga oleh masyarakat yang menganut agama lain. Namun, perlu digaris bawahi umat beragama lain hanya mengikuti kegiatan adat saja dan tidak mengikuti kegiatan agamanya. Hal ini menggambarkan bahwa masyarakat Bayan di KLU sangat menjunjung tinggi nilai toleransi, yakni dengan menghargai masyarakat yang menganut agama lain.

\section{b. Bebasan makanan}

Bebasan makanan berarti bahan makanan. Masyarakat yang mengikuti kegiatan maulid adat membawa dan menyerahkan sebagian sumber hasil bumi sebagai bahan makanan, hal ini dilakukan sebagai wujud rasa syukur kepada Tuhan atas segala limpahan rahmat dan rizkinya.

\section{c. Nazar}

Nazar merupakan niat atau keinginan masyarakat Bayan saat menyerahkan sebagian hasil bumi kepada Kiyai Lebe atau Inan Meniq. Hal ini menunjukkan bahwa masyarakat Bayan sangat mengerti bahwa manusia hanya membuat rencana sementara Tuhan yang mengabulkan segala keinginan harapan manusia.

\section{d. Menyembeq}

Menyembeq merupakan proses menandai dahi dengan sirih yang dilakukan oleh Kiyai Lebe atau Inan Meniq yang bemakna merestui atau mengaminkan setiap nazar yang disampaiakan oleh masyarakat yang datang. Poses ini memang terlihat melawan agama karena seolah-olah manusia yang mengabulkan keinginan manusia lainnya, namun pada hakekatnya tidak seperti itu. Prosesi menyembeq yang dilakuakan oleh Kiyai Lebe atau Inan Meniq ini mencerminkan sebuah perantara saja, dimana Tuhan menciptakan manusia yang satu dengan yang lainnya untuk saling menolong, saling membimbing satu sama lain dan Tuhan tidak secara langsung melimpahkan rahmat dan rizkinya kepada manusia melainkan melalui perantaraperantara lain yang ada di lingkungan manusia tersebut.

\section{e. Peresean}

Peresean yang dilaksanakan pada malam 15 Rabiul Awal di halaman Masjid Kuno merupakan sebuah acara tradisional 
suku Sasak yang biasa dilakukan oleh para pepadu (jawara). Namun pada mulud adat, siapa saja yang ingin bertarung diperbolehkan. Permainan yang digelar di depan Masjid Kuno Bayan ini tidak didasari rasa dendam, namun merupakan ritual dan sebagai hiburan MAB sejak berabad-abad lalu. Peresean menandakan bagaimana jerih payah perjuangan Rasulullah SAW dalam mengajarkan atau menyampaikan ajaran Islam dan membimbing umatnya untuk mengahadapi perang Badar dan Uhud.

\section{f. Praja Mulud}

Praja Mulud merupakan pemuda adat yang didandani menyerupai sepasang penganting yang diiring dari rumah "Pembekel Beleq Bat Orong" (pemangku adat dari Bayan Barat) menuju Masjid Kuno dengan membawa sajian berupa hidangan seperti nasi dan lauk pauk dengan menggunakan ancak. Praja mulud ini menggambarkan proses terjadinya perkawinan langit dan bumi, Adam dan Hawa yang disimbolkan dengan pasangan pengantin yang dilakukan oleh pemuda dan pemudi masyarakat Adat Bayan.

\section{g. Khotbah}

Khutbah merupakan kegiatan ceramah yang disampaikan kepada orang Islam yang dalam hal ini adalah masyakat Bayan dengan syarat dan rukun, baik berupa peringatan, pembelajaran atau nasihat agama dan tentunya dalam MAB adalah mengenai khutbah agama kelahiran nabi
Muhammad SAW. Dalam prosesi khutbah dipimpin atau dilakukan oleh tokoh agama, yakni oleh Kiyai Lebe atau Kiyai Santri serta ditutup dengan dzikir dan doa.

\section{Leksikon yang Berhubungan dan Berkaitan dengan Alam}

\section{a. Maulid Adat Bayan}

Pada dasarnya Maulid Adat ini tentu saja juga berkaitan dengan alam, kerena baik bahan makanan dan lokasinya serta rumah adat tempat berlangsungnya kegiatan, semuanya berasal dari alam, bahkan dalam prosesi tertentu seperti penebangan pohon bambu dan mencuci beras harus dilakuakn ritual betabiq, yakni penghormatan kepada alam. Ini artinya Masyarakat Bayan sangat menghargai alam dalam prosesi MAB.

\section{b. Bebasan Makanan}

Bahan makanan yang diserahkan masyarakat dari hasil bumi tidak hanya berhubungan dengan wujud rasa syukur kepada Tuhan, tetapi juga merupakan keterkaitan antara masyarakat dengan alam. Hal ini membuktikan bahwa masyarakat Bayan sangat bergantung pada alam, padahal di sisi lain dengan perkembangan zaman dan teknologi banyak sekali tersedia makanan ataupun jajanan praktis yang dijual di pasar ataupun di toko, akan tetapi masyarakat Bayan lebih memilih Bahan makanan yang tersedia di alam lingkungan sekitar mereka. Dan ini juga menunjukkan bahwa masyarakat Bayan adalah masyarakat yang sederhana dan mencintai 
lingkungannya.

\section{c. Mbisoq Rontok}

Rontok merupakan tempat yang digunakan untuk menumbuk padi yang terbuat dari kayu yang berbentuk sampan. Rontok ini harus dibersihkan dahulu sebelum digunakan, kerena hanya digunakan sekali setahun atau hanya pada tradisi MAB. Bentuknya yang menyerupai sampan ini menyimbolkan kehidupan manusia di dunia harus seimbang, seperti perahu di tengah lautan, manusialah yang menetukan keseimbangan dan kemana arah perahu itu akan berlayar. Begitu pula di daratan bahwa manusia harus menjaga dan melestarikan lingkungan agar tidak rusak dan hancur, sehingga tetap bermanfaat bagi kehidupan.

\section{d. Buang Unggun}

Sekam (sese) padi yang dikumpulkan di atas balen unggun tersebut dibuang ke sungai Masaan Segah yang letaknya sekitar 400 meter dari kampu Karang Bajo. Dedaq beserta sekam itu diyakini oleh masyarakat Bayan sebagai penyubur ikan yang ada di sungai. Kaum perempuan membawa sekam dan dedaq sedangkan kaum Pria membawa tempan (Alat untuk menumbuk padi yang tersebut dari bambu) untuk dibersihkan di sungai setelah digunakan menumbuk padi.

\section{e. Umbul-umbul}

Umbul-umbul terbuat dari bambu dan akan dipasang di setiap sudut dengan ujung
Umbul-umbul menghadap ke Masjid Kuno. Proses pencarian tunggul ini dipimpin oleh seorang pemangku yang disebut "Melokaq Penguban". Proses ini dilakukan setelah mendapat perintah dari Inan Meniq yaitu dengan pemberian lekoq buaq (sirih dan pinang) oleh Inan Meniq kepada Melokaq Penguban. Lekoq buaq ini merupakan suatu alat sebagai media bertabiq kepada pohon bambu yang akan di tebang. Bambu oleh masyarakat adat Bayan dimanfaatkan pada setiap prosesi adat di dalam Kampu, bahkan sering dijadikan sebagai kuliner dan bahan bangunan. Pada bangunan Masjid Kuno Bayan, bambu digunakan sebagai atap (santek). Demikian juga dengan pagar keliling Masjid kuno juga terbuat dari bambu. Pada bangunan rumah Adat, bambu selain dimamfaatkan sebagai usuk dan pagar inan bale, juga dijadikan sebagai pagar rumah, pengikat kayu dan atap serta sebagai daun pintu.

Dalam prosesi ritual adat bambu memiliki peran yang sangat besar yaitu, dijadikan sebagai pemotong pusar bagi bayi yang baru lahir dan sebagai tempat menaruh benang pati dalam acara potong rambut (ngurisan) dan dalam prosesi khitanan atau potong loloq. Saat penyerahan saji krama acara pernikahan, bambu dijadikan ancak saji sebagai tempat menaruh makanan. Begitu juga saat ada yang meninggal dunia, bambu dijadikan sebagai keranda jenazah (gorong batang) sekaligus sebagai penopang tanah pada liang lahad. Semua prosesi ritual yang dilaksanakan komunitas 
Bayan, bambu tidak boleh hilang, seperti pada maulid adat, lebaran adat, membangar dan mituk (7 hari kematian). Fungsi bambu juga dijadikan alat memancing bagi nelayan. Jenis bambu ini dikenal dengan biloq. Sementara bambu yang baru tumbuh (rembong-istilah Bayan) dapat dikonsumsi sebagai bahan makanan untuk sayur. Selain itu bambu seringkali digunakan sebagai penopang lantai bangunan bertingkat. Keterkaitan lain antara masyarakat Bayan dengan bambu adalah bambu merupakan tumbuhan yang hidup tumbuh lurus ke atas yang nantinya diharapkan masyarakat Bayan juga menjadi masyarakat yang jujur dan lurus. Selain itu bambu yang tumbuh besar ke atas juga befungsi melindungi atau menjaga bambu-bambu kecil lainnya dan bambu yang hidup berumpun atau berkelompok. Hal ini berhubungan dengan keinginan masyarakat bayan yang ingin saling melindungi, mengayomi masyarakat di sekelilingnya dan saling membimbing satu sama lainnya.

\section{f. Menampah Hewan}

Seperti halnya bahan makanan yang diserahkan masyarakat, hewan juga termasuk hasil ternak yang diserahkan masyarakat Bayan pada tradisi MAB. Hewan ini meupakan hewan ternak, seperti sapi, kerbau, bebek dan ayam. Semua hewan ini nantinya akan disembelih dan dimasak untuk disajikan kepada seluruh masyarakat yang mengikuti MAB pada puncak acara.

\section{g. Ancak}

Ancak adalah tempat yang digunakan untuk mengageq dan membawa hidangan ke Masjid Kuno. Ancak terbuat dari bambu, berbentuk persegi dan dibuat oleh kaum pria. Selain itu, ancak ini merupakan tempat menaruh sesuatu hidangan pada saat acara makan bersama di Masjid Kuno oleh para pemuka Agama Adat, sedangkan untuk masyarakat adat makan bersama di dalam kampu dengan menggunakan dulang dan piring seperti biasanya.

\section{h. Memblonyo}

Memblonyo merupakan kegiatan pemberian tanda kepada Masyarakat Adat oleh wanita dari keturunan yang ikut dalam proses majang (menghias) tersebut. Blonyo ini adalah minyak yang terbuat dari kelapa yang dibuat oleh masyarakat Bat Orong karena Bat Orong dan Timuq Orong dalam fungsi sosial adat Bayan bertugas mengurus kegiatan yang behubungan dengan akhirat, seperti agama, keyakinan, gaib dan hal-hal mistik, dimana kelapa tersebut dibawa oleh masyarakat Adat Karang Bajo, karena Karang Bajo dan Ancak bertugas mengerjakan hal-hal yang berkaitan dengan samawi atau dunia, sehingga segala persiapan dikerjakan oleh masyarakat dari Karang Bajo dan Ancak. Pembuatan minyak belonyo ini dilakukan selama dua hari dan dipercaya mempunyai khasiat untuk mengobati segala macam penyakit. Ini menunjukkan bahwa tumbuhtumbuhan di alam ini sangat bermanfaat 
bagi kehidupan manusia, selain digunakan untuk lauk-pauk, dan bahan bangunan, juga bisa digunakan sebagai obat-obatan.

\section{i. Peralatan-peralatan lainnya}

Ada banyak hal lainnya juga behubungan dengan alam, selain dari yang dipaparkan di atas, yakni berkaitan dengan peralatan-peralatan seprti: keraro, tempan, lesung, balen unggun, grege, dan daun gol. Keraro merupaka alat untuk membawa beras yang akan dicuci di sungai, keraro ini berbentuk bundar menyerupai bak atau ember yang terbuat dari anyaman bambu. Masyarakat Bayan lebih memilih bakul daripada bak atau ember dikarenakan bakul lebih praktis, kerena ketika mencuci beras di sungai, wanita-wanita yang mencuci beras tidak perlu memindahkan beras dari wadah yang satu ke wadah yang lain karena bentuk bakul yang bundar dan jarang (lubang-lubang kecil), sehingga air sungai dengan sendirinya akan menghanyutkan kotoran dari beras yang dicuci melalui lubang-lubang kecil tersaebut. Tempan merupakan alat untuk menumbuk padi yang tebuat dari bambu. Lesung meupakan tempat untuk menumbuk padi menjadi beras, yang terbuat dari kayu berbentuk silinder lonjong dengan lubang di tengahnya sebagai tempat padi ditumbuk. Balen unggun merupakan tempat untuk menaruh sese (sisa atau kotoran dari padi yang sudah ditumbuk) yang terbuat dari bambu yang dibentuk dan diangkai seperti meja. Daun gol dalam bahasa Indonesia yakni daun Bidara dipercayai oleh masyarakat Bayan dapat mengusir makhluk halus, sehingga tidak mengganggu berlangsungnya seluruh rangkaian prosesi adat.

\section{Leksikon yang Berhubungan dan Berkaitan dengan Manusia (sosial)}

\section{a. Maulid Adat Bayan}

Maulid adat selain berhubungan dengan kegiatan agama dan adat juga berhubungan dengan sesama manusia, yakni untuk menjalin silaturrahmi yang baik kepada seluruh masyarakat, baik sesama masyarakat Bayan maupun dengan masyarakat lainnya.

\section{b. Bebasan Makanan}

Bahan makanan yang akan dihidangkan pada puncak acara ini berasal dari seluruh masyarakat yang mengikuti tradisi maulid adat, artinya tidak diberatkan pada pihak manapun. Hal ini bermakna adanya hubungan kerjasama yang baik antara seluruh masyarakat demi kelancaran kegiatan maulid adat.

\section{c. Ngalu Gerantung}

Ngalu Gerantung adalah proses penjemputan gong dan alat musik lainnya dari kampu Bat Orong (Bayan Barat) karena Grantungan meupakan alat musik yang mempunyai kekuatan mistik sehingga harus disimpan di Orong Bat dan penjemputan dilakukan oleh warga masyarakat adat Karang Bajo karena 
masyarakat Karang Bajo bertugas mempersiapkan hal-hal yang berkaitan dengan dunia, yakni alat Gamelan yang dijemput digunakan sebagai hiburan masyarakat pada acara $\mathrm{MAB}$ dan sebagai pengiring pada saat acara seperti, menutu dan peresean (temetian), setelah rombongan penjemput Gerantung tiba di Kampu lokasi dilaksanakan acara penyambutan dan serah terima dengan ngaturang lekesan (sirih dan pinang), barulah acara ritual Taikan Mulud dimulai.

\section{d. Pamaq}

Pamaq merupakan gabungan dari lekoq, buaq dan apur. Secara umum sirih pada masyarakat bayan berati keakraban. Namun ada filosofi lain yang terselip dalam sirih tersebut, yakni lekoq bemakna kulit manusia, membungkus tulang putih yaitu apur dan daging yang diwakili oleh buah pinang, lalu jadi air yang bewarna merah yang berarti darah. Pamaq ini digunakan untuk menyembeq mayrakat sebagai tanda di dahi, mengapa di dahi dekat dengan ubun -ubun, karena dahi dekat ubun-ubun merupakan pusat dari mental manusia, dengan menandai di dahi diharapkan dapat memberikan efek semangat dan menumbuhkan motivasi seta mental seseoang untuk mencapai tujuab dan keinginannya.

\section{e. Mbisoq Rontok}

Mbisoq rontok selain berhubungan dengan alam juga berhubungan dengan kerjasama antara sesama manusia, dimana mbisoq rontok ini dilakukan oleh seluruh panitia laki-laki MAB yang nantinya akan digunakan oleh para wanita sebagai tempat untuk menumbuk padi.

\section{f. Menutu}

Proses menutu ini dilakukan oleh kaum perempuan dan dilaksanakan setelah “Gugur Kembang Waru” sekitar jam 15.30 waktu setempat. Alat-alat yang digunakan adalah tempan yang terbuat dari bambu dan lesung perahu (rantok) yang terbuat dari kayu. Kaum perempuan yang ikut dalam proses menutu harus menggunakan busana yang berbeda dengan yang lainnya, yaitu dengan menggunakan jong (ikat kepala perempuan). Adapun mengapa harus perempuan yang menumbuk padi bukan laki-laki, hal ini berhubungan dengan bahwa, pada hakekatnya wanitalah yang melahirkan manusia di muka bumi dalam keadaan suci tak bedosa, sehingga wanitalah yang menumbuk, membersihkan padi menjadi beras.

\section{g. Umbul-umbul}

Umbul-umbul yang terbuat dari bambu tutul akan dipajang pada setiap pojok dengan ujung umbul-umbul menghadap Masjid Kuno. Proses pencarian tutul ini dipimpin oleh seorang pemangku yang disebut "Melokaq Penguban". Pencarian tunggul ini dilakukan oleh lima orang, dimana empat sebagai pembawa tunggul, yaitu dari keturunan penguban, pembekel, 
melokaq gantungan rombong, pande, dan satu orang dari kalangan masyarakat adat sebagai pembawa bambu ikat. Ini menunjukkan adanya kerjasama antara seluruh lapisan masyarakat bayan dan mempunyai tanggung jawabnya masingmasing. Sebagaimana filosofi masyarakat Bayan, berat sama dipikul, ringan sama dijinjing.

\section{h. Ngengelat}

Pada malam harinya bertepatan dengan bulan purnama, para pemimpin adat dan Agama mulai melaksanakan ngengelat yaitu mendandani ruangan Masjid Kuno dengan kain yang memiliki simbol-simbol sarat (penuh) makna. Kain yang berwarna putih dan biru dipasang pada langit-langit Masjid Kuno yang bermakna suci dan damai, sedang kain yang lainnya dipasang pada empat tiang Masjid tersebut yang bermakna bahwa dunia penuh dengan berbagai macam cobaan dan rintangan, namun manusia harus tetap berjuang dan berusaha untuk menjadi lebih baik.

\section{i. Mbisoq Meniq}

Mbisoq Meniq merupakan proses membersihkan beras yang sudah dibersihkan (tempik) dengan iringaniringan panjang para perempuan adat dengan rapi berbaris dengan bakulbakul beras di kepala menuju sungai "Masaan segah" yang jaraknya sekitar 400 meter dari Kampu Karang Bajo. Proses pencucian beras ini dipimpin oleh Inan Aiq dan dalam perjalanan tidak boleh saling mendahului. Sebelum pencucian beras Inan Aiq akan melakukan doa atau bertabiq kepada sungai dengan mengaturkan buaq lekesan setelah pengaturan buaq lekesan selsai, barulah prosesi pencucian beras dimulai, adapun dalam kegiatan mencuci beras tidak boleh saling mendahului hal ini berhubungan dengan nilai tumaq ninah, yakni yang dahulu didahulukan kemudian diikuti oleh yang selanjutnya. Ini juga mengandung makna bahwa masyarakat Bayan sangat menghormati para leluhur dan orang-orang lebih tua. Sebagai syarat yang boleh mencuci beras ini adalah perempuan yang suci (tidak dalam masa haid), ini merupakan syarat wajib perempuan yang boleh mencuci beras, karena dikhawarkan darah haid hanyut di sungai dan dapat mengotori beras yang dicuci.

\section{j. Mengkelaq}

Mengkelaq merupakan kegiatan memasak, baik itu memasak nasi maupun lauk pauk. Dalam prosesi memasak dilakukan oleh laki-laki dan perempuan. Laki-laki memasak lauk pauk sementara perempuan memasak nasi. Laki-laki yang memasak dikenal istilah Amaq Pedangan atau Ran, sementara perempuan yang memasak dikenal dengan istilah Inan Pedangan. Ini merupakan nilai kebersamaan saling tolong menolong dan kerjasama semua masyarakat Bayan dalam kegiatan MAB. 


\section{k. Mengageq}

Mengageq yaitu menata hidangan di atas sebuah tempat yang terbuat dari bambu, yang dirancang sedemikian rupa yang disebut dengan "ancak" serta menata hidangan diatas "sampa" yang terbuat dari kayu, yang nantinya dihidangkan pada saat acara di Masjid Kuno dan acara meriap di Berugaq Agung. Mengageq ini dilakukan oleh kaum perempuan, sementara kaum laki -laki yang akan bertugas untuk membawanya ke Masjid Kuno.

\section{l. Meriap}

Meriap adalah makan bersama di Berugaq Agung yang dihadiri oleh para undangan yang berasal dari Bat Orong, Plawangan, Timuq Orong, dan Pemuka Agama dan Adat dari Karang bajo. Meriap dipimpin oleh Kiyai Lebe yang dipesilaq (Permintaan) dari Melokaq Gantungan Rombong. Meriap tersebut dilayani oleh panitia adat dan semua makanan dihidangkan di sampaq.

\section{m. Melusut}

Melusut adalah membuka kembali pajangan (kain yang menghiasi Berugaq Agung) oleh masyarakat setelah pajangan tersebut selesai dibuka maka seluruh rangkaian acara Mulud Adat selesai dan masyarakat kembali kerumah masingmasing.

\section{n. Pakaian}

Selama prosesi maulid adat, masyarakat harus menggunakan pakaian sesuai dengan ketentuan adat, yakni laki-laki harus menggunakan sapuq, kereng belo dan kemben, sementara perempuan harus menggunakan jong atau cipoq, kereng belo dan kemben, dan semua masyarakat yang mengikuti prosesi maulid adat tidak diperbolehkan menggunakan pakaian dalam dan perhiasan, hal ini dilakukan supaya tidak terjadi kesenjangan sosial antara yang kaya dan miskin.

Dari pemaparan di atas dapat ditemukan ekologi sosial yakni masyarakat dari Karang Bajo dan Ancak bertugas mengurus keperluan dan persiapan yang menyangkut samawi atau dunia, sedangkan Orong Bat dan Timuq Orong bertugas melaksanakan hal-hal yang berkaitan dengan akhirat, Agama, gaib dan hal-hal mistik. Sehingga diperoleh sebuah kesimpulan bahwa kedudukan masyarakat Orong Bat dan Orong Timuq lebih tinggi daripada masyarakat Karang Bajo dan Ancak.

\section{Revitalisasi Bahasa Sasak yang Menan-} dai Tradisi MAB sebagai Suplemen

\section{Pembelajaran Bahasa Indonesia Berbasis} Lingkungan di SMA

Revitalisasi bermakna menghidupi atau memberdayakan kembali satuan-satuan lingual kultural secara kontekstual dalam kehidupan masyarakat. MAB selain mengandung kegiatan agama, juga mengandung nilai adat dan budaya. Jika ini bisa dikembangkan dan dipelihara MAB ini sangat berpotensi untuk dijadikan sebagai 
budaya pariwisata dan bisa mendongkrak perekonomian masyarakat Bayan. Upaya lain pencegahan pergeseran atau kepunahan melalui pemberdayaan atau pengajaran tentang MAB baik di lingkungan formal maupun nonformal. Pada lingkungan formal, peneltian ini diharapkan bisa menjadi suplemen pembelajaran bahasa Indonesia berbasis lingkungan.

Tujuan hasil penelitian ini dijadikan sebagai bahan ajar adalah agar dapat memberikan bekal pengetahuan, keterampilan dan prilaku yang terkandung dalam MAB kepada peserta didik. Jadi yang akan direvitalisasi dalam penelitian ini adalah leksikon, makna-makna leksikon dan urutan prosesi MAB yang akan dibuat atau dituangkan dalam pembelajaran teks di SMA. Dengan demikian, peserta didik memiliki wawasan tentang keadaan lingkungan dan kebudayaan masyarakat sesuai dengan nilai-nilai atau aturan-aturan yang berlaku di daerahnya. Selain itu, pembelajaran bahasa Indonesia berbasis lingkungan diharapkan dapat mendukung kelangsungan pembangunan daerah dan melestarikan kekayaan daerahnya. Dalam hal ini kekayaan yang dimaksud adalah leksikon bahasa dan budaya yang terdapat dalam MAB di Bayan. Dengan memberikan pelajaran bahasa Indonesia berbasis lingkungan berbahan ajar leksikon yang digunakan dalam MAB di Bayan, siswa diharapkan 1) siswa dapat mengenal dan menjadi lebih akrab dengan lingkungan sosial dan budayanya, 2) siswa memiliki pengetahuan, kemampuan dan keterampilan mengenai daerahnya yang berguna bagi dirinya maupun lingkungan masyarakat, 3) siswa memiliki sikap dan prilaku yang selaras dengan nilai-nilai atau aturan-aturan yang berlaku di daerahnya, 4) siswa membantu dalam melestarikan dan mengembangkan nilai-nilai luhur budaya setempat dalam rangka menunjang pembangunan nasional.

\section{SIMPULAN}

Simpulan pertama, satuan-satuan lingual khazanah leksikon MAB di lingkungan masyarakat Bayan terfokus pada bentuk dan kategori. Bentuk leksikon berdasarkan data yang diperoleh, leksikon bentuk tunggal, bentuk kompleks (afiksasi dan reduplikasi) dan bentuk majemuk, yang termasuk bentuk tunggal seperti ares, jong, dan sapuk, sedangkan yang termasuk dalam bentuk kompleks terbagi atas; 1) kelompok leksikon berafiks seperti menyembeq, memajang, dan seKeraro; 2) kelompok kata ulang seperti umbul-umbul dan oram-oram; 3) kelompok leksikon termasuk bentuk majemuk sepertibatun dupa, inan meniq, dan kereng belo; Adapun kategori leksikon-leksikon MAB tersebut adalah kategori nomina, verba, dan numeralia. 1) Kategori nomina dikelompokkan menjadi kategori nomina biotik (inan meniq, bedus, dan manuk) dan abiotik (atep, Keraro, dan bongot).

Simpulan kedua, ditemukan leksikonleksikon yang mempunyai makna dan keterkaitan terhadap lingkungan masyarakat 
Bayan, baik yang behubungan dengan $\mathrm{Tu}-$ han, alam, dan sosial, seperti menyembeq ini adalah untuk menyampaikan tujuan masing-masing masyarakat kepada Allah SWT lewat perantara Kiyai Lebe, Inan Meniq, dan sembeq tersebut merupakan pertanda bahwa masing-masing orang telah menyampaikan tujuannya hidup dan sebagai tanda kedatangan mereka untuk mengikuti ritual Mulud Adat agar mereka mendapat keselamatan pada saat melaksanakan ritual Mulud Adat ataupun setelahnya. Praja Mulud ini menggambarkan proses terjadinya perkawinan langit dan bumi, Adam dan Hawa yang di simbolkan dengan pasangan pengantin yang dilakukan oleh pranata-pranata Adat Bayan, presean merupakan sebuah acara tradisional suku Sasak yang biasa dilakukan oleh para pepadu (jawara) yang dilaksanakan pada malam tanggal 15 Rabiul Awal di halaman Masjid Kuno menandakan, bagaimana jerih payah perjuangan Rasulullah SAW dalam mengajarkan atau menyampaikan ajaran islam dan membimbing umatnya untuk mengahadapi perang Badar dan Uhud. Dan mbelonyo merupakan kegiatan pemberian tanda kepada Masyarakat Adat oleh wanita dari keturunan yang ikut dalam proses majang tersebut, minyak ini terbuat dari kelapa yang dibuat oleh masyarakat Bat Orong, di mana kelapa tersebut dibawa dari masyarakat Adat Karang Bajo. Pembuatan minyak belonyo ini dilakukan selama dua hari dan dipercaya mempunyai khasiat untuk mengobati segala macam penyakit.

Simpulan ketiga adalah upaya revitalisasi leksikon-leksikon MAB yang diwujudkan pada hasil penelitian ini dan diharapkan nantinya bisa digunakan sebagai suplemen bahan pembelajaran bahasa Indonesia berbasis lingkungan di SMA, khususnya di Bayan Kabupaten Lombok Utara. Suplemen bahan ajar tersebut dibuat dalam bentuk pembelajaan teks, yakni teks laporan observasi, di mana dalam teks tersebut memuat tentang leksikon prosesi serta makna dan nilai-nilai yang terkandung dalam MAB. Tujuan dijadikannya bahan ajar agar hasil penelitian ini dapat memberikan bekal pengetahuan kepada peserta didik supaya memiliki wawasan tentang bahasa dan budaya di lingkunganya dan mampu menerapkan nilai-nilai agama dan sosial yang berlaku di daerahnya.

\section{UCAPAN TERIMA KASIH}

Penulis mengucapkan terima kasih kepada Mitra Bebestari atas kritik dan masukan yang membangun untuk perbaikan artikel ini.

\section{DAFTAR PUSTAKA}

Duranti, A. 1997. Linguistik Antropology. Cambridge: Cambridge University Press.

Mahsun. 2011. Metode Penelitian Bahasa: Tahapan Strategi, Metode, dan Tekniknya. Jakarta: Rajawali Pers.

Mbete, Aron Meko. 2003. Bahasa dan Budaya Lokal Minoritas "asal muasal ancaman kepunahan dan ancangan pemberdayaan dalam kerangka pola ilmiah pokok kebudayaan. Denpasar: Universitas Udayana.

Mbete, Aron Meko. 2007. Ekolinguistik: Persepektif Kelinguistikan yang Prospek- 
tif. Bahan untuk Berbagi Pengalaman Kelinguistikan dalam Kuliah Umum Mahasiswa Jurusan Bahasa dan Seni, Fakutas Bahasa dan Senu Universitas Negeri Semarang.

Mbete, Aron Meko. 2013. Penuntun Singkat Penulisan Proposal Penelitian Ekolinguistik. Denpasar: Vidia.

Muhlhausler, Peter and Alwin Fill (Eds.) 2001. The Ecolinguistics Reader. Language, Ecology and Environment. London and New York: Continuum.

Sibarani, R. 2004. Antropolinguistik. Medan:
Poda.

Sinar, Tengku Silvana, 2010. "Ungkapan Verbal Etnis Melayu dalam Pemeliharaan Lingkungan." Disampaikan dalam Seminar Internasional Seminar Language, Literature, And Culture in Southheast Asia.

Sukri, Muhammad dan Rusdiawan. 2008. Bahasa dalam Realitas Sosial. Mataram: Lembaga Cerdas Press.

Verhar, J. W. M. 2010. Asas-Asas Linguistik Umum. Yogyakarta: Gajah Mada University Press. 